\title{
Heat Release Imaging in Turbulent Premixed Ethylene-Air Flames Near Blow-off
}

\author{
J. Kariuki ${ }^{1}$ (D) . A. Dowlut ${ }^{2}$. R. Balachandran ${ }^{2}$. \\ E. Mastorakos ${ }^{1}$
}

Received: 15 October 2015 / Accepted: 12 February 2016

(C) The Author(s) 2016. This article is published with open access at Springerlink.com

\begin{abstract}
The focus of this work is to visualise the regions of $\mathrm{CH}_{2} \mathrm{O}$ and heat release (HR) of an unconfined turbulent premixed bluff body stabilised ethylene-air flame at conditions approaching lean blow-off using simultaneous imaging of $\mathrm{OH}-$ and $\mathrm{CH}_{2} \mathrm{O}-\mathrm{PLIF}$. The HR regions are estimated from the product of the $\mathrm{OH}$ and $\mathrm{CH}_{2} \mathrm{O}$ profiles. At conditions near blow-off, wide regions of $\mathrm{CH}_{2} \mathrm{O}$ are observed inside the recirculation zone (RZ). The presence of $\mathrm{CH}_{2} \mathrm{O}$ and $\mathrm{HR}$ inside the $\mathrm{RZ}$ is observed to follow fragmentation of the downstream flame parts near the top of the RZ. The presence of wide regions void of both $\mathrm{OH}$ and $\mathrm{CH}_{2} \mathrm{O}$ inside the $\mathrm{RZ}$ at conditions very close to blow-off indicates the possible entrainment of un-reacted gases into the RZ. The behaviour of the lean ethylene-air flame with Lewis number $(L e)$ greater than 1 is compared to that of a lean methane-air flame with $L e$ of approximately 1 . For both fuels, qualitatively similar observations of flame fragmentation downstream followed by build-up of $\mathrm{CH}_{2} \mathrm{O}$ and $\mathrm{HR}$ inside the $\mathrm{RZ}$ are observed at conditions near lean blow-off. Also, a similar trend of flame front curvature conditioned on HR was observed for both the ethylene-air and methane-air flames, where the magnitude of HR was observed to increase with the absolute value of curvature.
\end{abstract}

Keywords $\mathrm{CH}_{2} \mathrm{O} \cdot \mathrm{PLIF} \cdot$ Premix $\cdot$ Heat release

\section{Introduction}

In the combustion literature, simultaneous imaging of PLIF of $\mathrm{OH}$ and $\mathrm{CH}_{2} \mathrm{O}$ has been demonstrated to be a useful technique to visualise regions of heat release (HR) in premixed

J. Kariuki

jmk62@cam.ac.uk

1 Hopkinson Laboratory, Engineering Department, University of Cambridge, Cambridge CB2 1PZ, UK

2 Department of Mechanical Engineering, University College London, London WC1E 7JE, UK 
flames [1]. It allows for a qualitative study of the reaction zone, while the individual profiles of $\mathrm{CH}_{2} \mathrm{O}$ - and $\mathrm{OH}-\mathrm{PLIF}$ also provide useful information concerning regions of partially reacted and burned gases respectively. Such measurements are particularly useful when investigating combustion processes characterised by finite rate chemistry effects, such as lean extinction, where the presence of $\mathrm{CH}_{2} \mathrm{O}$ allows for identification of regions undergoing low temperature combustion processes.

Paul et al. [2] demonstrated that the profile of the pixel-by-pixel product of simultaneously obtained $\mathrm{OH}$ - and $\mathrm{CH}_{2} \mathrm{O}$-PLIF images correlates well with $\mathrm{HR}$ rates in premixed flames. Their work built on that performed by Najm et al. [3] which showed that the formyl radical HCO correlates very well with HR in laminar premixed flames. Unfortunately, insufficient LIF signal intensities of HCO limits its measurement, particularly in turbulent reacting flows [3]. However, $\mathrm{HCO}$ production is dependent on $\mathrm{OH}$ and $\mathrm{CH}_{2} \mathrm{O}$ radicals in the flame front. Both $\mathrm{OH}$ and $\mathrm{CH}_{2} \mathrm{O}$ radicals occur in sufficiently high number densities, permitting their measurement using nanosecond pulsed laser systems. Taking the product of their PLIF profiles allows for a qualitative visualisation of the HR regions in premixed flames [2].

The applicability of this technique to turbulent premixed flames has been demonstrated by Böckle et al. [4] who studied both a turbulent Bunsen flame and a strongly turbulent swirling flame. For the turbulent Bunsen flame, the overlapping regions of the planar $\mathrm{OH}$ and $\mathrm{CH}_{2} \mathrm{O}$ profiles correlated well with areas of intermediate temperatures identified from Rayleigh temperature measurements. The HR imaging technique has also been applied to both forced and unforced lean premixed flames by Balachandran et al. [1] and Ayoola et al. [5]. The high spatial resolution obtainable using the technique permitted a detailed analysis of the local flame front structure and the relationship between curvature and HR [5], and on the flame response to inlet velocity oscillations [1]. These are only a select few of the studies that have used PLIF imaging of $\mathrm{OH}$ and $\mathrm{CH}_{2} \mathrm{O}$ to obtain useful insight into various combustion processes in premixed and non-premixed gaseous and spray systems.

The problem of lean extinction has received growing interest over recent years due to the development of lean burn premixed combustion technologies. These technologies offer advantages such as reduced fuel utilisation and pollutant emissions. However, one of the challenges that arise when operating flames near their lean limit is flame blow-out. The problem of flame blow-out, also referred to as blow-off, has been studied since the late 1940 's, though it is still not well understood [6]. Also, detailed information on the flame structure at conditions close to lean blow-off is not readily available in the literature to the extent of that of flames at conditions away from extinction, whose behaviour is well summarised by Driscoll [7]. Recent studies have used laser diagnostics, which can offer high spatial and temporal resolution, to obtain detailed measurements of flames near lean blow-off [6, 8-10]. However, measurement of the $\mathrm{OH}$ radical is commonly favoured, with less information available on the $\mathrm{CH}_{2} \mathrm{O}$ profile in relevant premixed flame configurations near the lean limit.

In previous work [10], simultaneous $\mathrm{OH}$ - and $\mathrm{CH}_{2} \mathrm{O}$-PLIF measurements were obtained for a lean premixed bluff-body stabilised methane-air flame at conditions approaching lean blow-off. Visualisation of the $\mathrm{CH}_{2} \mathrm{O}$ signal provided useful information on the increasing presence of low temperature combustion processes inside the recirculation zone as the lean extinction limit is approached. The product of the $\mathrm{OH}$ and $\mathrm{CH}_{2} \mathrm{O}$ profiles provided a qualitative understanding of the locations of HR and the degree to which the HR regions became disconnected at conditions near blow-off which is harder to observe from the $\mathrm{OH}$ image alone. Building on the previous work, further experiments have been performed in the same burner configuration, but substituting the methane fuel for ethylene. Ethylene is particularly 

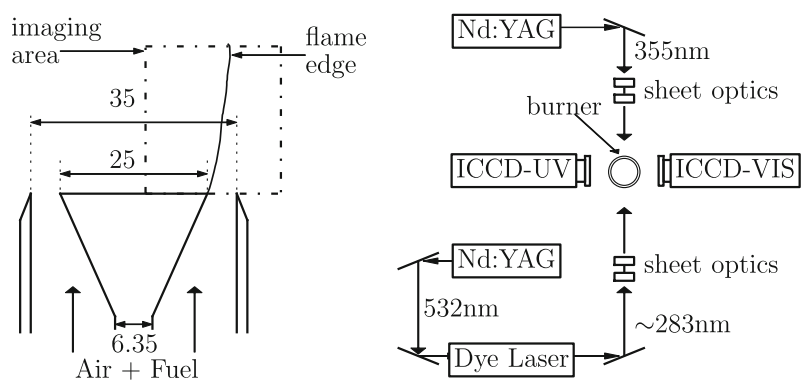

Fig. 1 (Left) Schematic of the bluff body combustor. All dimensions in mm. (Right) Layout of the PLIF systems

advantageous for HR imaging measurements as a higher number of density of $\mathrm{CH}_{2} \mathrm{O}$ radicals are produced during the combustion process compared to the combustion of methane. Also, ethylene is a practical alternative to methane when a fuel with higher burning velocity or higher stoichiometric air-to-fuel ratio is desired, and has been used in various studies of unforced and forced premixed flames [5]. In this work, ethylene is used to investigate the effect of varying mixture chemistry on the lean extinction behaviour of premixed flames. In particular, knowledge of the effect of the higher laminar burning velocity and above unity Lewis number $L e$ for a lean ethylene-air flame, compared to a lean methane-air flame, on the $\mathrm{CH}_{2} \mathrm{O}$ and $\mathrm{HR}$ profiles at conditions near lean blow-off is both interesting and useful to better understand the combustion fundamentals of finite rate reaction conditions and for model validation purposes.

\section{Experimental Methods}

\subsection{Apparatus and flow conditions}

Figure 1 shows a schematic of the bluff body burner used. A stainless steel conical bluff body of diameter $d=25 \mathrm{~mm}$ and $45^{\circ}$ half-angle was mounted on a rod of diameter 6.35 mm centred inside an inlet pipe of length $300 \mathrm{~mm}$ and inner diameter $D=35 \mathrm{~mm}$. A fully premixed ethylene-air mixture is supplied to the burner, with the air and fuel flow rates controlled using Vögtlin Instruments mass flow controllers. The exit of the burner was profiled to a knife-edge and was open to the lab atmosphere. PLIF measurements of the flame are obtained at four conditions, starting from a condition far from blow-off (B1), to a condition just prior to blow-off (B4). These conditions are presented in Table 1.

\section{$2.2 \mathrm{OH}-$ and $\mathrm{CH}_{2} \mathrm{O}$-PLIF}

Figure 1 also shows the schematic of the PLIF systems. A low repetition Litron Nd:YAG laser is used to pump a Fine Adjustments Pulsare-S tunable-dye laser, within which a Rhodamine $6 \mathrm{G}$ dye solution is used to produce a beam at $566 \mathrm{~nm}$. This beam is then passed through a frequency doubler tuned to produce a beam near $283 \mathrm{~nm}$ to excite $\mathrm{OH}$. The output of a second Litron Nd:YAG laser at $1064 \mathrm{~nm}$ was frequency tripled to $355 \mathrm{~nm}$ to excite $\mathrm{CH}_{2} \mathrm{O}$. The pulse width of the pump lasers is approximately 10 to $12 \mathrm{~ns}$. A combination of a plano-concave lens and a bi-convex lens was used to expand each of the two beams 
Table 1 Summary of experimental conditions

\begin{tabular}{llll}
\hline Flame & $U_{b}[\mathrm{~m} / \mathrm{s}]$ & $\phi$ & $\delta_{L}[\mathrm{~mm}]$ \\
\hline B1 & 20.8 & 0.74 & 0.037 \\
B2 & 20.8 & 0.71 & 0.040 \\
B3 & 20.7 & 0.67 & 0.047 \\
B4 & 20.7 & 0.65 & 0.054 \\
\hline
\end{tabular}

$U_{b}$ is the bulk mixture velocity at the annular exit. $\delta_{L}$ is the laminar flame thickness $\left(v / S_{L}\right.$, where $v=1.54 \mathrm{E}-5$ and values of $S_{L}$ are obtained from [11], their Fig. 3a.)

into a thin vertical sheet. The height and thickness of the laser sheet used to excite $\mathrm{OH}$ was approximately $30 \mathrm{~mm}$ and $200 \mu \mathrm{m}$ respectively, while that of the laser sheet used to excite $\mathrm{CH}_{2} \mathrm{O}$ was approximately $25 \mathrm{~mm}$ and $300 \mu \mathrm{m}$ respectively.

Identical TSI CCD cameras $(1376 \times 1024$ pixel resolution at $8 \mathrm{~Hz})$ were used to record the two PLIF signals. One of these cameras was coupled with a UV intensifier, fitted with a Cerco 2178 UV lens $(100 \mathrm{~F} / 2.8)$ and a band pass filter $(309-375 \mathrm{~nm})$ created using a combination of WG305 and UG11 Schott glass filters to record OH. The second camera was coupled to a visible intensifier fitted with a Nikkon lens $(50 \mathrm{~F} / 1.2)$ and a band pass filter (395-610 nm) created using a combination of GG 395 and BG 40 filters to record $\mathrm{CH}_{2} \mathrm{O}$. Both $\mathrm{OH}$ and $\mathrm{CH}_{2} \mathrm{O}$ acquisition systems were operated at $5 \mathrm{~Hz}$, with both intensifiers gated at $200 \mathrm{~ns}$. The $\mathrm{CH}_{2} \mathrm{O}$ laser system was triggered after a delay of $300 \mathrm{~ns}$ after triggering of the $\mathrm{OH}$ laser system. The effective spatial resolution of the acquired $\mathrm{OH}$ - and $\mathrm{CH}_{2} \mathrm{O}$-PLIF images was approximately $25 \times 25 \times 200 \mu \mathrm{m}$ per pixel and $25 \times 25 \times 300 \mu \mathrm{m}$ per pixel respectively. At each flame condition, 200 image pairs of $\mathrm{OH}-$ and $\mathrm{CH}_{2} \mathrm{O}-\mathrm{PLIF}$ were recorded and saved for post processing.

\subsection{Image analysis}

The following steps were performed as part of the post-processing of the $\mathrm{OH}$ - and $\mathrm{CH}_{2} \mathrm{O}$ PLIF images to estimate the HR profile. Initially, the background noise was subtracted from the recorded images and filtering was performed using a $3 \times 3$ median filter. Correction of the laser sheet profile was then performed using the ensemble-average image of the laser sheets passing through a cuvette filled with ethanol obtained separately from the flame measurements. Identical reference points along the PLIF measurement plane were selected from target images obtained for each camera and used to define a transformation matrix relating the coordinate sets of the two cameras. This transformation matrix was then used to match the coordinate set of the OH-PLIF acquisition camera to that of the $\mathrm{CH}_{2} \mathrm{O}$-PLIF acquisition camera. The corrected and matched PLIF images were then resized using $2 \times 2$ binning, resulting in an effective spatial resolution of approximately $50 \times 50 \times 300 \mu \mathrm{m}$ per pixel. The HR profile was then obtained from the product of the $\mathrm{OH}$ and $\mathrm{CH}_{2} \mathrm{O}$ images.

\section{Results}

Instantaneous images of the PLIF of $\mathrm{OH}$ and $\mathrm{CH}_{2} \mathrm{O}$ for the ethylene-air flame at the condition furthest away from blow-off, B1, are shown in Fig. 2(top row, a-c). The edge of the 
B1

$\mathrm{B} 2$

B3

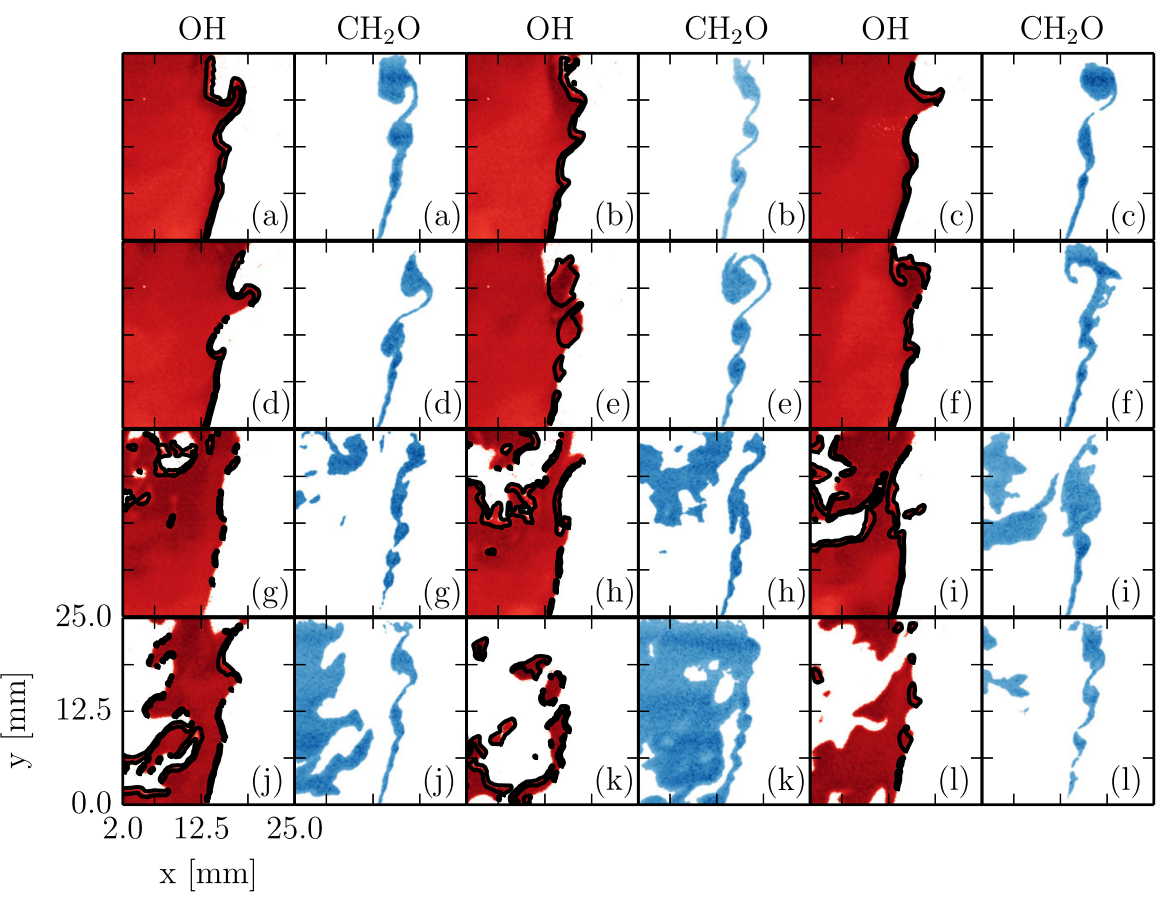

Fig. 2 Instantaneous PLIF images for flames B1 to B4 (rows top to bottom). The region of HR is shown by thick black lines superimposed on the $\mathrm{OH}$ image

OH-PLIF signal marks the boundary between the unburned and burned gases, and therefore marks, tentatively, the flame front. At this condition, the region of recirculating gases behind the bluff body is filled with $\mathrm{OH}$, indicating the presence of hot combustion products in this region. The $\mathrm{CH}_{2} \mathrm{O}$-PLIF signal is observed along the annular jet of reactants, adjacent to the flame front, where pre-heated gases are expected. The thin region of overlap of $\mathrm{OH}$ and $\mathrm{CH}_{2} \mathrm{O}$ is shown by thick black lines superimposed on the $\mathrm{OH}$ image and marks, qualitatively, the region of HR. This region is mostly continuous and smoothly wrinkled. Occasionally, vortex-like structures appear along this region, causing the width of the $\mathrm{CH}_{2} \mathrm{O}$ and $\mathrm{HR}$ profiles to increase locally in the region between the flame surfaces created as preheated reactants are transported towards the flame front by these structures. These observations are similar to those reported previously in experimental investigations of the HR behaviour of turbulent lean premixed ethylene-air flames [5] and methane-air flames [10] at conditions far from lean extinction.

The flame at condition B2 is shown in Fig. 2(second row from top, $d-f$ ). The profiles of the $\mathrm{OH}-$ and $\mathrm{CH}_{2} \mathrm{O}-\mathrm{PLIF}$ signals at this condition are similar to those at condition $\mathrm{B} 1$. The OH-PLIF signal extends from the flame front into the RZ, and the $\mathrm{CH}_{2} \mathrm{O}$-PLIF signal is located adjacent to the flame front along the annular jet of fresh reactants. The HR region remains mostly continuous and smoothly wrinkled. However, there is a slight increase in the frequency and size of the breaks occurring along this region. These breaks are not easily observed from the OH-PLIF signal alone, and may be localised extinctions occurring along the flame front. However, out-of-plane motion of the flame with respect to the planar laser sheets may also lead to the appearance of breaks along the imaging plane, particularly at locations away from the attachment point. 
At conditions closer to blow-off, B3, shown in Fig. 2(third row from top, g-i), significant changes start to appear in the $\mathrm{OH}$ - and $\mathrm{CH}_{2} \mathrm{O}$-PLIF signals. The OH-PLIF signal is more disconnected, particularly at the downstream parts of the RZ where regions void of $\mathrm{OH}$ are observed, which were filled with $\mathrm{OH}$ at conditions $\mathrm{B} 1$ and $\mathrm{B} 2$. Isolated regions of $\mathrm{OH}$ also appear at these downstream locations, indicating local disintegration of the downstream flame parts. The $\mathrm{CH}_{2} \mathrm{O}$-PLIF signal no longer occurs primarily along the annular jet of reactants, and wide regions of $\mathrm{CH}_{2} \mathrm{O}$ are observed at the downstream parts of the RZ. In most cases, regions void of $\mathrm{OH}$ at the downstream are filled with $\mathrm{CH}_{2} \mathrm{O}$. This seems to indicate the presence of partially-reacted gases where the flame locally extinguishes, whereas at conditions further from blow-off, this region was filled with hot combustion products. $\mathrm{HR}$ is observed to occur at the inner shear layer along the annular reactants jet, towards the downstream end of the RZ where the partially reacted gases come into contact with hot combustion products and along the boundary of isolated pockets of $\mathrm{OH}$. Similar observations for the methane-air flame were also reported in [10], where, qualitatively, it appears that the ethylene-air flame is more disconnected at the downstream regions as blow-off is approached, with a greater build-up of $\mathrm{CH}_{2} \mathrm{O}$ observed, qualitatively, at the downstream end of the RZ.

For the flame closest to blow-off, condition B4, shown in Fig. 2(bottom row, j-1), greater changes are observed in both the $\mathrm{OH}-$ and $\mathrm{CH}_{2} \mathrm{O}$-PLIF signals. The $\mathrm{OH}-\mathrm{PLIF}$ signal is more fragmented, and regions void of $\mathrm{OH}$ inside the $\mathrm{RZ}$ are also observed near the bluff body surface. On occasion, the flame can disintegrate significantly, such as in Fig. 2k, but the flame at the attachment point is re-established and the flame survives at this condition very close to blow-off. Wide regions of $\mathrm{CH}_{2} \mathrm{O}$ are also observed in the RZ, mainly coinciding with regions void of any $\mathrm{OH}$. Also, regions void of both $\mathrm{OH}$ and $\mathrm{CH}_{2} \mathrm{O}$ are observed, Fig. 2l, though this occurs significantly less often. This seems to indicate that at conditions very close to blow-off, wide regions of the RZ are filled with partially reacted gases, and on occasion, entrainment of completely un-reacted gases may occur, resulting in the regions void of both $\mathrm{OH}$ and $\mathrm{CH}_{2} \mathrm{O}$. As observed at condition B3, HR occurs along the shear layer at the annular jet of reactants, inside the $\mathrm{RZ}$ where the downstream flame parts reside and along the boundary of isolated pockets of $\mathrm{OH}$.

These instantaneous images show that local disintegration of the flame downstream coincides with the presence of partially reacted gases inside the RZ. The manner in which the wide regions of $\mathrm{CH}_{2} \mathrm{O}$ form inside the $\mathrm{RZ}$ is not clear. They may indicate pre-heated reactants entrained from the shear layer, or form as the result of fresh reactants entrained from the annular jet mixing with hot combustion products inside the RZ. Additionally, if extinction of the premixed flame begins at the burnt side, then the consumption of $\mathrm{CH}_{2} \mathrm{O}$, which occurs in the high temperature region of the flame, may be frozen, causing the $\mathrm{CH}_{2} \mathrm{O}$ radicals to survive for some duration. This may also explain the overlap of wide regions filled with both $\mathrm{OH}$ and $\mathrm{CH}_{2} \mathrm{O}$ inside the RZ, where the surviving overlapping $\mathrm{OH}$ and $\mathrm{CH}_{2} \mathrm{O}$ may indicate the presence of quenched gases. It will be interesting to see if computational models can capture this behaviour observed at lean mixture conditions, particularly the entrainment of gases from the top of the $\mathrm{RZ}$ and the wide regions of $\mathrm{CH}_{2} \mathrm{O}$ in the $\mathrm{RZ}$, as such results may offer insight to the onset of low temperature combustion processes inside the RZ.

Figure 3 shows the average $\mathrm{OH}-$ and $\mathrm{CH}_{2} \mathrm{O}$-PLIF profiles, and average HR $\left(\mathrm{OH} \times \mathrm{CH}_{2} \mathrm{O}\right)$, for conditions $\mathrm{B} 1$ to $\mathrm{B} 4$. The mean PLIF profiles agree with observations from the instantaneous images. At conditions $\mathrm{B} 1$ and $\mathrm{B} 2$, the $\mathrm{RZ}$ is filled with $\mathrm{OH}$, and $\mathrm{CH}_{2} \mathrm{O}$ is observed along the shear layer. The mean flame brush, marked by the profile of the average HR, is observed to be relatively thin at the attachment point, where the HR intensity appears highest, and broadens further downstream. At condition B3, wide regions of 


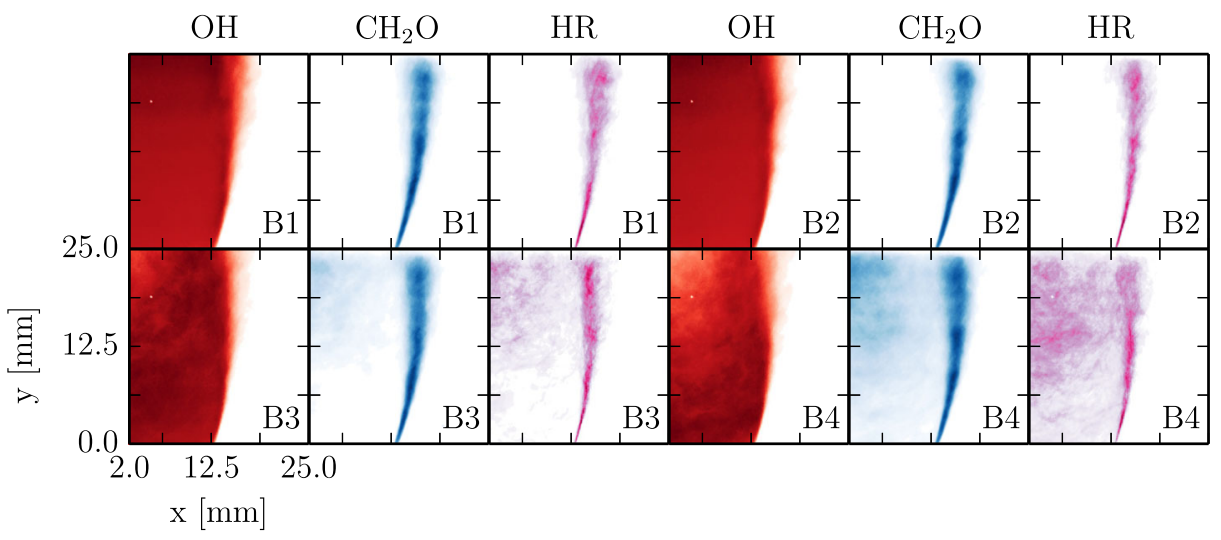

Fig. 3 Mean PLIF images for flames B1 to B4

$\mathrm{CH}_{2} \mathrm{O}$ are observed towards the downstream parts of the $\mathrm{RZ}$ where $\mathrm{OH}$ and $\mathrm{HR}$ are present. At condition B4, very close to blow-off, $\mathrm{CH}_{2} \mathrm{O}$ is observed over a larger section of the $\mathrm{RZ}$, including near to the attachment point on the bluff body edge. A wider averaged HR profile is also observed inside the RZ, indicating that the majority of the reaction is no longer located along the shear layer. The $\mathrm{OH}$ signal at the downstream parts of the RZ near the centerline is also observed to be weaker, indicating local quenching of the flame.

Similar observations were reported for a lean premixed methane-air flame approaching blow-off in the same burner configuration [10]. In these measurements, significant parts of the $\mathrm{RZ}$ at conditions close to blow-off were observed to be filled with $\mathrm{CH}_{2} \mathrm{O}$, which were filled with $\mathrm{OH}$ at higher equivalence ratios. Also, the wide regions of $\mathrm{CH}_{2} \mathrm{O}$ in the $\mathrm{RZ}$ occurred in regions void of $\mathrm{OH}$, and regions void of both $\mathrm{OH}$ and $\mathrm{CH}_{2} \mathrm{O}$ were also observed, but less occasionally, inside the RZ at conditions near blow-off. For both the ethylene- and methane-air flames, $\mathrm{CH}_{2} \mathrm{O}$ build-up in the $\mathrm{RZ}$ begins downstream where the flame starts to disintegrate. As the flame becomes more fragmented, the amount of $\mathrm{CH}_{2} \mathrm{O}$ inside the $\mathrm{RZ}$ increases. Wide regions of $\mathrm{CH}_{2} \mathrm{O}$ are then observed inside the $\mathrm{RZ}$ when the downstream flame parts have crossed into the RZ where reaction is now occurring. For the unconfined configuration investigated, entrainment of air from the ambient may be important to the build-up of $\mathrm{CH}_{2} \mathrm{O}$ in the RZ. However, as in the methane flame previously investigated [10], no evidence of $\mathrm{CH}_{2} \mathrm{O}$ penetrating the shear layer adjacent to the annular jet at conditions away from blow-off (B1 to B3) indicate that propagation of the flame attached to the bluff body edge is sufficient to close holes arising from local extinctions in this region. However, entrained air may lead to leaner mixture conditions downstream where the flame begins to fragment and build-up of $\mathrm{CH}_{2} \mathrm{O}$ begins. Detailed experimental and numerical studies on the local equivalence ratio would give clearer insight to this. It is also worth examining the curvature of the ethylene-air flame, and this is discussed below.

From the PLIF images, the effect of flame front curvature on HR was investigated. The edge of the OH-PLIF profile was taken to mark the flame front. The extracted flame front contour was initially divided into 1 pixel length segments and filtered using a zero-phase digital filter with a filter length of 5 . The filtered flame front was then superimposed on the HR image, and the intensity of HR along a line normal to the tangent of the flame front at each point was evaluated. A length of $1 \mathrm{~mm}$ was chosen as the integrating length for $\mathrm{HR}$ along the flame normal. The two-dimensional flame front curvature was calculated using 
the method described by Haq et al. [12]. With ' $s$ ' denoting the length of the flame front measured from a fixed origin on the filtered contour, the first and second derivatives in the $x$ and $y$ directions along the flame front with respect to $s$ were evaluated and filtered using the same zero-phase digital filter. Values of the local curvature along the flame front conditioned on heat release were then calculated using $\kappa=\dot{x} \ddot{y}-\dot{y} \ddot{x} /\left(\dot{x}^{2}+\dot{y}^{2}\right)^{3 / 2}$, where $\dot{x}=d x / d s$ and $\ddot{x}=d^{2} x / d s^{2}$. With the flame front detected on the reactant side of the flame, the curvature is positive where the radius of curvature of the flame front is convex to the reactants, and negative where the radius of curvature is concave to the reactants.

The probability density function $(p d f)$ of the local two-dimensional curvature for flames B1 to B4 are shown in Fig. 4a. A non-dimensional measurement of flame front curvature is obtained from taking the product of the curvature values with the corresponding laminar flame thickness $\delta_{L}$ for each experimental condition. The $\mathrm{OH}$ laser sheet thickness, of approximately $200 \mu \mathrm{m}$, limits the curvature that can be resolved to approximately $5 \mathrm{~mm}^{-1}$. The values of $\delta_{L}$ used are shown in Table 1. The distributions of $\kappa \delta_{L}$ are observed to be approximately Gaussian, and are symmetric about $\kappa=0$. At conditions approaching blowoff, the $p d f \mathrm{~s}$ are seen to widen. Similar results were also reported by Ayoola et al. [5] for lean ethylene-air flames where the flame front was defined from the edge of the HR profile. Also, similar distributions of $\kappa \delta_{L}$ for the methane-air flame was reported in [10]. Bin averaged values of the average HR detected along the flame normal for values of $\kappa \delta_{L}$ are shown in Fig. $4 \mathrm{~b}$, where a bin width of $\kappa \delta_{L}=0.1$ was chosen. Values are reported where the bin sizes exceeded 200 points in order to reduce error from random scatter. From the plot, HR is observed to increase as a function of the absolute value of flame front curvature, with a stronger increase in HR observed for positive curvatures and higher equivalence ratios. Ayoola et al. [5] also reported an increase in HR with the absolute value of curvature for a confined premixed ethylene-air flame at conditions away from blow-off, but not at conditions near blow-off where HR was observed to decrease monotonically with increasing curvature. The reason for this difference is not clear, and an examination of the uncertainties in the integrated HR profiles is useful.

Considering errors arising from LIF quenching conditions, although no direct estimation has been performed in this study, estimates can be obtained from the literature. Uncertainties arising from collisional quenching rates of OH LIF are typically reported to be below $20 \%[13,14]$. However, limited information is available on collisional quenching rates for $\mathrm{CH}_{2} \mathrm{O}$ LIF. Calculations of lean freely propagating laminar ethylene-air flames performed by Ayoola et al. [5] showed the quenching cross sections of $\mathrm{CH}_{2} \mathrm{O}$ PLIF, using transition
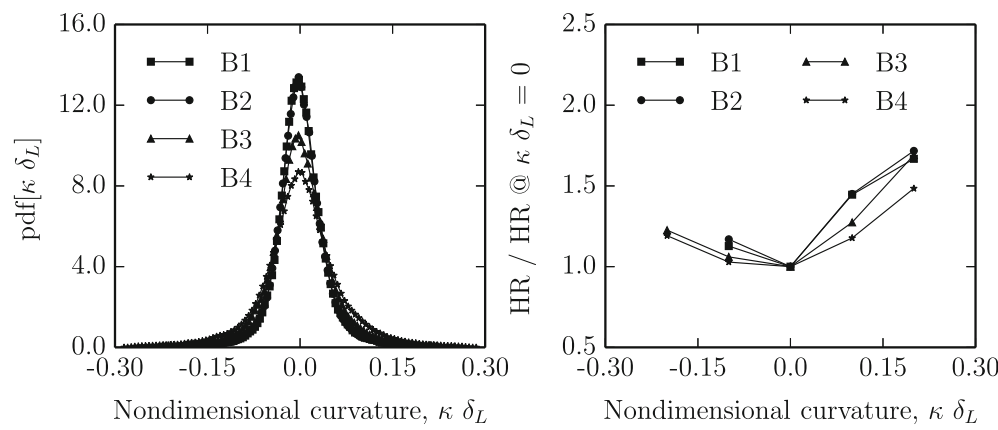

Fig. 4 (a, Left) pdfs of curvature and (b, Right) plots of HR against curvature for flames B1 to B4 
lines near $353 \mathrm{~nm}$, to have little dependence on flame temperature for values between 900 $1500 \mathrm{~K}$ over which the majority of the overlap of $\mathrm{OH}$ and $\mathrm{CH}_{2} \mathrm{O}$ occurs. Although the present study uses the excitation of the weaker rotational transition of $\mathrm{CH}_{2} \mathrm{O}$ at $355 \mathrm{~nm}$, we can reasonably assume similar quenching conditions given the narrow range of flame temperatures relevant to the qualitative HR estimates. Additionally, the higher beam energies attained at $355 \mathrm{~nm}$ have been shown to offset the lower absorption efficiency at this transition line to achieve sufficient concentration profiles to enable reliable HR estimates [13]. Uncertainties in the beam energy shot-to-shot variation are also important to the LIF concentration profiles. For the PLIF results reported in this study, the signal-to-noise ratio varied from 2 to 4 . The standard deviation of the spatial average of the LIF signal intensity calculated for each flame image within a set of 200 images for each condition is less than $7 \%$ of the mean of the spatial average LIF signal intensities for the entire set. This indicates that the shot-to-shot variation of the laser energy may not be significant compared to general experimental uncertainties. Additionally, the shot-to-shot laser variation was monitored using photodiodes during image acquisition and no significant changes were detected. Therefore, we can consider the uncertainties associated with the qualitative HR results presented here to be sufficiently small to enable reasonable interpretation of general trends of the integrated HR profiles.

Also, the results reported for the ethylene-air flame here are similar to those reported for the methane-air flame. This may be unexpected considering the different Lewis numbers of the fuels discussed earlier. Numerical simulations performed by Chakraborty and Cant [15] showed that the reaction component of flame displacement is negatively correlated with curvature for flames with $L e=1.2$, while for flames with $L e=1$, no clear correlation is observed. This is in agreement for the methane-air flame but not for the ethylene-air flame. A clearer trend may be obtained from more quantitative results, whereas the qualitative estimation of the HR in this study and the errors associated with using the two-dimensional curvature from the planar measurements to estimate the three-dimensional flame topology may not give a reliable trend of the effect of flame curvature on HR.

\section{Discussion}

From these observations, it appears that the disintegration behaviour of the ethylene- and methane-air flames at conditions very close to blow-off is qualitatively similar. The problem of turbulent premixed flame extinction is often reduced to a competition between the fluid-mechanical and chemical processes in the turbulent reacting flow [8]. The competition of these processes are often described using time and length scales of chemistry and turbulence, which are compared using dimensionless groups. One such approach often used is the regime diagram of turbulent premixed combustion as defined by Peters [16], shown in Fig. 5 for both the ethylene- and methane-air flames studied here and in previous work [10] respectively. In the diagram, the chemical processes are described by the unstretched laminar flame speed $S_{L}$ and thickness $\delta_{L}$, while the fluid-mechanical scales are described by the magnitude of the characteristic turbulence fluctuation $u^{\prime}$ and the integral length scale of turbulence $L_{T}$. Velocity information for the methane-air flame was obtained in previous work [9] where the method used to estimate $u^{\prime}$ and $L_{T}$ is described. To summarise, $L_{T}$ was evaluated using a two-point correlation of the axial turbulent velocity fluctuation $u_{R M S}$. To account for the anisotropic turbulence local to the flame stabilised in the shear layer, the axial turbulent velocity fluctuation at selected points along the mean flame front location was correlated along 8 vectors orientated at $45^{\circ}$ intervals. These were then integrated until the first crossing 


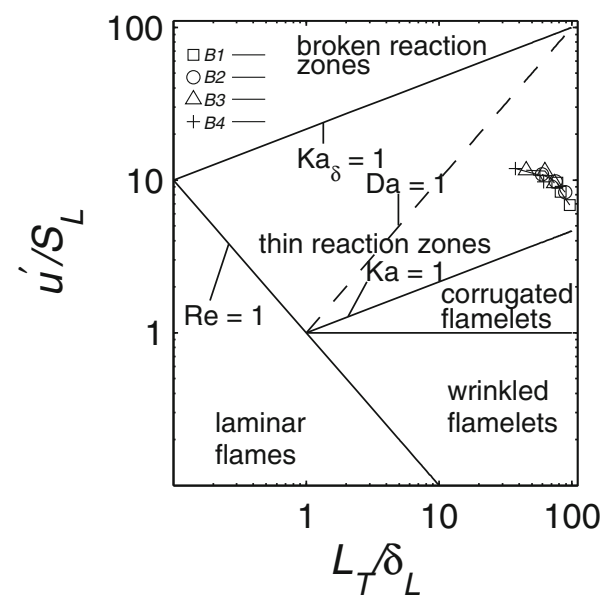

(a)

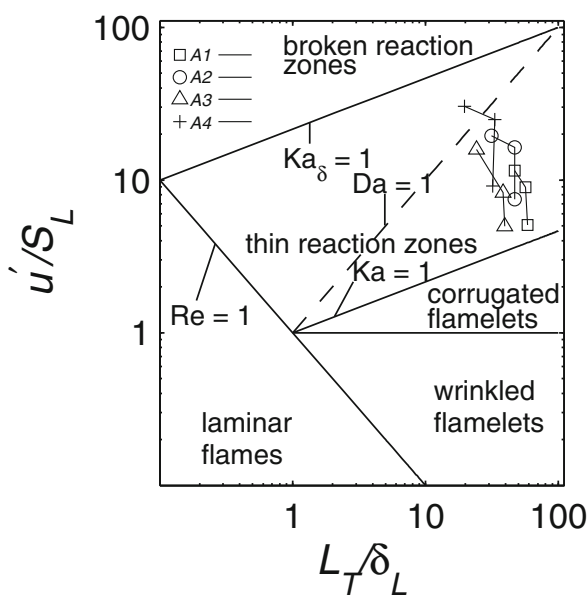

(b)

Fig. 5 Regime diagrams of turbulent premixed combustion as defined by Peters [16] along the $\bar{c}=0.5$ contour for (left) flames B1 to B4 and (right) a premixed methane-air flame at similar conditions. Conditions $\mathrm{A} 1, \mathrm{~A} 2, \mathrm{~A} 3$ and A4 correspond to $U_{b}=21.6,21.5,21.4$ and $21.4 \mathrm{~m} / \mathrm{s}$ and $\phi=0.75,0.70,0.67$ and 0.64 respectively. Values of $U_{b}$ and $\phi$ for conditions B1 to B4 are given in Table 1

of the $x$-axis to give the integral lengthscale along each of the 8 directions. Their average was evaluated to give a local estimate of $L_{T}$ at the selected flame front locations. For a threedimensional velocity field, $u^{\prime}$ can be defined by $3 / 2 u^{\prime 2}=1 / 2\left(u_{R M S}^{2}+v_{R M S}^{2}+w_{R M S}^{2}\right)$. $u_{R M S}, v_{R M S}$ and $w_{R M S}$ are the RMS velocity fluctuations in the axial, radial and tangential directions respectively. From the two-dimensional PIV data obtained in [9], and assuming $w_{R M S}^{2}=v_{R M S}^{2}$ for the present configuration, an estimate of $u^{\prime}$ was defined as $\sqrt{\left(u_{R M S}^{2}+2 v_{R M S}^{2}\right) / 3}$.

As the burner geometry used in the methane- and ethylene-air flame studies is identical, and that the bulk mixture exit velocities are also similar (approximately $0.7 \mathrm{~m} / \mathrm{s}$ lower for the ethylene-air flame), we can expect similar burner aerodynamics in both studies. From observing that the flame location within the flow field is also similar for both the ethyleneand methane-air flames, we can expect the two flames to experience similar turbulence conditions. Additionally, in the methane-air flame study, the velocity field showed very little differences for the mixture conditions investigated, where $\phi$ ranged between 0.64 and 0.75. Similar conditions are also investigated for the ethylene-air flame in the present work. Therefore, we can approximate crude estimates of turbulent parameters for the ethylene-air flame from the velocity data obtained for the methane-air flame. For simplicity, estimates of $u^{\prime}$ and $L_{T}$ for flames B1 to B4 are obtained from velocity data for flames A1 to A4 respectively, presented in [9]. The turbulent parameters are estimated along the isocontour of mean progress variable $\bar{c}=0.5$. The mean progress variable map was evaluated from the ensemble average of binary images of the OH-PLIF profile obtained using a suitable threshold as described in [9]. The results for conditions B1 to B4 are presented in Fig. 5, together with results of the methane-air flame approaching blow-off. An identical imaging region of the ethylene-air flame, shown in Fig. 1, was used in the study the methane-air flame reported in [10]. 
From Fig. 5a, the ethylene-air flame is located in the thin reaction zone regime, similarly to the methane-air flame in Fig. 5b. However, while the ethylene-air flame within the imaged region remains in the $D a>1$ region for the conditions investigated, the methane-air flame at conditions very close to blow-off (A4) crosses into the $D a<1$ region. Here, $D a$ is the turbulent Damköhler number as defined by Peters [17] as $\left(L_{T} / \delta_{L}\right) /\left(u^{\prime} / S_{L}\right)$. This is interesting given that for both fuels, the downstream part of the $\bar{c}=0.5$ contour is located inside the RZ, and the degree of fragmentation for both the ethylene- and methane-air flames appears qualitatively similar at conditions very close to blow-off. Noting that the imaged region extends $1 d$ downstream, where $d=25 \mathrm{~mm}$ is the bluff body diameter, estimates of the parameters investigated in Fig. 5 do not provide a complete description of the flame behaviour. This is as from the PIV data with the methane-air flame [9], values of $u^{\prime}$ at the shear layer $1 d$ downstream are typically around $0.15-0.2 U_{b}$, while higher values around $0.25 U_{b}$ are observed further downstream at the location of the maximum flame brush height of approximately $1.6 d$ for conditions near blow-off. In addition to considering other factors affecting $D a$, which are discussed shortly, slightly lower values of $D a$ can be expected along the downstream parts of the ethylene flame not investigated in the present work. However, the higher unstretched laminar flame speed of ethylene compared to methane may explain why the ethylene-air flame lies lower in the thin reaction zone regime, whilst the smaller laminar flame thickness, $\delta_{L}=v / S_{L}$, would shift the location of the ethylene-air flame to the right, away from the $D a=1$ boundary.

The trend of the leaner ethylene-air flame approaching the $D a=1$ boundary observed in Fig. 5a results from the reduction in flame speed and migration of the flame brush to regions of higher turbulence intensity. However, the scales of chemistry used here do not take into account some physical processes that may significantly affect the burning rate of the flame. Such processes include entrainment of the ambient air along the outer shear layer, which may reduce the local equivalence ratio downstream, and the entrainment of relatively cool gases into the RZ. These may significantly affect the volumetric heat loss of the flame and act to reduce its burning rate. Consequently, the value of the local $D a$ along the flame front may be lower than that indicated in Fig. 5a. Also, the instantaneous position of the flame front away from the attachment point can vary considerably, as observed for flame B3 and B4, which together with the inhomogeneous nature of the turbulence in the present burner geometry make it difficult to describe the complete behaviour of the flame with a few points on the regime diagram.

However, given the significant separation of the ethylene-air and methane-air flames on the regime diagram, the aforementioned factors must have a significant influence at very near blow-off conditions for the ethylene-air flame to enter the $D a<1$ region. Therefore, other pertinent factors should be considered. Lewis number effects may also be important in explaining the qualitatively similar level of fragmentation observed for the ethylene-air flame for values of $D a$ greater than unity compared to the methane-air flame where extinction occurs at $D a$ values close to unity. Law [18] showed that for $L e>1$ flames, such as the lean ethylene-air flames studied here, strain alone can cause extinction, whereas flames with $L e<1$ require heat loss, incomplete combustion or high rates of flame curvature for extinction to occur. The lean methane-air flames investigated here have $L e$ values of approximately 0.98 [19]. Increased heat loss and incomplete combustion would correspond to longer chemical timescales relative to the fluid-mechanical timescales which, if required by the methane-air flame, would cause it to extinguish at smaller values of $D a$ than perhaps the ethylene-air flame assuming both experience similar levels of aerodynamic stretch. Detailed experimental or numerical studies investigating pertinent factors including heat loss and turbulence local to the instantaneous flame front are required for 
further clarification and would provide a more accurate mapping on the turbulent regime diagram.

\section{Conclusions}

Simultaneous measurements of $\mathrm{OH}-$ and $\mathrm{CH}_{2} \mathrm{O}$-PLIF have been performed to visualise the formaldehyde signal and regions of HR for a turbulent premixed ethylene-air flame close to the lean extinction condition. At conditions away from blow-off, $\mathrm{CH}_{2} \mathrm{O}$ was observed along the annular reactants jet, and the region of HR was mostly thin and continuous. As the blow-off condition was approached, fragmentation of the HR region was observed to begin at the downstream flame regions. This coincided with a build up of $\mathrm{CH}_{2} \mathrm{O}$ locally where the flame disintegrated. At conditions closer to blow-off, flame fragmentation occurred closer to the attachment point on the bluff body edge, and wide regions of $\mathrm{CH}_{2} \mathrm{O}$ were observed inside the RZ. In most cases, regions void of $\mathrm{OH}$ inside the $\mathrm{RZ}$ were filled with $\mathrm{CH}_{2} \mathrm{O}$. However, wide regions void of both $\mathrm{OH}$ and $\mathrm{CH}_{2} \mathrm{O}$, and also regions filled with both $\mathrm{OH}$ and $\mathrm{CH}_{2} \mathrm{O}$ were also observed inside the $\mathrm{RZ}$. This seems to indicate the entrainment of both partially reacted and completely un-reacted gases into the RZ from the downstream parts of the RZ, leading to the presence of low temperature combustion processes inside the RZ at conditions very close to lean extinction. The flame behaviour was discussed with reference to the regime diagram of turbulent premixed combustion and also compared to previous work where a premixed methane-air flame was studied. Qualitatively similar behaviour are observed for the two different fuels, whilst their locations within the thin reaction zone regime differ slightly. The effect of flame front curvature on HR was also investigated, where the magnitude of HR was observed to increase with the absolute value of curvature, with a stronger trend observed for positive curvatures, and a decrease in HR with leaner mixture conditions. These measurements are useful for model validation in computational studies investigating the near-extinction behaviour of premixed flames, and for developing our understanding of the changes in the structure of turbulent premixed flames as lean extinction is approached.

Acknowledgments Dr Balachandran and Mr Dowlut gratefully acknowledge support from EPSRC for research grant EP/G063788/1 and UCL/EPSRC Doctoral Training Account respectively that enabled measurement methods presented here.

Open Access This article is distributed under the terms of the Creative Commons Attribution 4.0 International License (http://creativecommons.org/licenses/by/4.0/), which permits unrestricted use, distribution, and reproduction in any medium, provided you give appropriate credit to the original author(s) and the source, provide a link to the Creative Commons license, and indicate if changes were made.

\section{Compliance with Ethical Standards}

Funding Funding of this study was obtained from the Engineering and Physical Sciences Research Council (EPSRC), research grant EP/G063788/1, and the UCL/EPSRC Doctoral Training Account.

Conflict of interests The authors declare that they have no conflict of interest. 


\section{References}

1. Balachandran, R., Ayoola, B.O., Kaminski, C.F., Dowling, A.P., Mastorakos, E.: Experimental investigation of the nonlinear response of turbulent premixed flames to imposed inlet velocity oscillations. Combust. Flame 143, 37-55 (2005)

2. Paul, P.H., Najm, H.N.: Planar laser-induced fluorescence imaging of flame heat release rate. Proc. Combust. Inst 27, 43-50 (1998)

3. Najm, H.N., Paul, P.H., Mueller, C.J., Wyckoff, P.S.: On the adequacy of certain experimental observables as measurements of flame burning rate. Combust. Flame 113, 312-332 (1998)

4. Böckle, S., Kazenwadel, J., Kunzelmann, T., Shin, D.I., Schulz, C., Wolfrum, J.: Simultaneous singleshot laser-based imaging of formaldehyde, $\mathrm{OH}$, and temperature in turbulent flames. Proc. Combust. Inst 28, 279-286 (2000)

5. Ayoola, B.O., Balachandran, R., Frank, J.H., Mastorakos, E., Kaminski, C.F.: Spatially resolved heat release rate measurements in turbulent premixed flames. Combust. Flame 144, 1-16 (2006)

6. Shanbhogue, S.J., Husain, S., Lieuwen, T.: Lean blowoff of bluff body stabilized flames: scaling and dynamics. Prog. Energy Combust. Sci 35, 98-120 (2009)

7. Driscoll, J.F.: Turbulent premixed combustion: flamelet structure and its effect on turbulent burning velocities. Prog. Energy Combust. Sci 34, 91-134 (2008)

8. Chaudhuri, S., Kostka, S., Renfro, M.W., Cetegen, B.M.: Blowoff dynamics of bluff body stabilized turbulent premixed flames. Combust. Flame 157, 790-802 (2010)

9. Kariuki, J., Dawson, J.R., Mastorakos, E.: Measurements in turbulent premixed bluff body flames close to blow-off. Combust. Flame 159, 2589-2607 (2012)

10. Kariuki, J., Dowlut, A., Yuan, R., Balachandran, R., Mastorakos, E.: Heat release imaging in turbulent premixed methane-air flames close to blow-off. Proc. Combust. Inst 35, 1443-1450 (2015)

11. Park, O., Veloo, P.S., Egolfopoulos, F.N.: Flame studies of $\mathrm{C}_{2}$ hydrocarbons. Proc. Combust. Inst 34, 711-718 (2013)

12. Haq, M.Z., Sheppard, C.G.W., Woolley, R., Greenhalgh, D.A., Lockett, R.D.: Wrinkling and curvature of laminar and turbulent premixed flames. Combust. Flame 131, 1-15 (2002)

13. Gordon, R.L., Masri, A.R., Mastorakos, E.: Simultaneous Rayleigh temperature, $\mathrm{OH}-\mathrm{and} \mathrm{CH}_{2} \mathrm{O}-\mathrm{LIF}$ imaging of methane jets in a vitiated coflow. Combust. Flame 155, 181-195 (2008)

14. Röder, M., Dreier, T., Schulz, C.: Simultaneous measurement of localized heat-release with $\mathrm{OH} / \mathrm{CH}_{2} \mathrm{O}-$ LIF imaging and spatially integrated $\mathrm{OH}$ chemiluminescence in turbulent swirl flames. Proc. Combust. Inst 34, 3549-3556 (2013)

15. Chakraborty, N., Cant, R.S.: Influence of lewis number on curvature effects in turbulent premixed flame propagation in the thin reaction zones regime. Phys. Fluids 17, 105-20 (2005)

16. Peters, N.: Turbulent Combustion. Cambridge University Press, Cambridge (2000)

17. Peters, N.: Laminar flamelet concepts in turbulent combustion. Proc. Combust. Inst 21, 1231-1250 (1986)

18. Law, C.K.: Dynamics of stretched flames. Proc. Combust. Inst 22, 1381-1402 (1989)

19. Hawkes, E.R., Chen, J.H.: Direct numerical simulation of hydrogen-enriched lean premixed methane-air flames. Combust. Flame 138, 242-258 (2004) 